\section{LAS VESTALES ANTE LOS PODERES PÚBLICOS ROMANOS}

VESTALS BEFORE PUBLIC ROMAN POWERS

Andrés Pociña

Universidad de Granada

\section{Resumen:}

Abstract:

En la Roma antigua las mujeres, incluso las In ancient Rome the women, even those pertenecientes a las clases superiores, no belonging to the upper classes, do not enjoyed gozaron nunca del reconocimiento de plenos the recognitiion of full citizen's rights, being derechosciudadanos, estanapartadas siempre always remote from public offices and de los cargos políticos y de gobierno. En el government. In the powerful world of the poderoso mundo de los sacerdocios, el único importante concedido a las mujeres, el colegio de las Vestales, demuestra con su historia y sus exigencias una vez más la relegación legal de las mujeres romanas.

\section{Palabras claves:}

Mujeres romanas, poderes

sacerdocios femeninos, Vestales.

Roman women, political powers, feminine políticos, priesthoods, Vestals.
La intención de este pequeña aproximación al significado del más significativo sacerdocio femenino de la Roma antigua, el colegio de las vírgenes vestales, responde al deseo de ofrecer un punto de comparación entre la situación política de las mujeres romanas clásicas y la de mujeres de otras épocas posteriores y otras latitudes, cosa que hago en paralelo con el trabajo presentado por Aurora López, dentro del conjunto de los ofrecidos por el equipo de investigación "Escritoras y Escrituras" de la Universidad de Sevilla, dirigido por Mercedes Arriaga, encaminados a estudiar desde la perspectiva de las mujeres los temas del Coloquio Internacional “Gouvernance, Citoyenneté et Etat de Droit", organizado por las universidades Abdelmalek Essaâdi de Tetuán, Sousse de Túñez, Sevilla y León. Si bien buena parte de las ponencias de dicho coloquio se presentaron y discutieron en lengua árabe, resultó obvio que las preparadas por mujeres y hombres, de diversas nacionalidades europeas, coordinadas por el grupo "Escritoras y Escritoras" marcaron una línea de atención absolutamente imprescindible, que de otra forma se hubiera pasado bastante por alto.

El texto que sigue no fue leído, por arbitraria decisión de la presidenta de la mesa de la sala en que estaba programada su presentación ${ }^{1}$. Recuerdo su nombre, pero no deseo introducirlo en un escrito mío. Le voy a dedicar, eso sí, dos breves textos de dos mujeres árabes a las que he conocido personalmente, he leído sus obras con provecho, y a las que admiro mucho desde hace tiempo, la egipcia Nawal Al-Sa'dawi y la marroquí Fátima Mernissi; ojalá las hubiera conocido también ella, y hubiera aprendido algo en sus páginas, como habría sido de esperar en una universitaria marroqui:

“El velo no es una cuestión religiosa, sino política. De hecho no vincula para nada con el islam, puesto que existe en el judaísmo y en el cristianismo. El velo se remonta a la época de la esclavitud. Mi padre se graduó en la Escuela Superior Islámica de Egipto y nunca me dijo que me pusiera el velo, y me envió a la Facultad de Medicina donde estudiaba con hombres. Los padres que fuerzan a sus hijas a llevar un velo en la cabeza desconocen lo que es el islam" .

Nawal Al-Sa'adawi ${ }^{2}$

"Lo que me enseñaron esas campesinas, obreras, videntes... es que las mujeres populares, las mujeres proletarias de Marruecos, están más avanzadas que las

\begin{abstract}
1 El Coloquio Internacional “Gouvernance, Citoyenneté et Etat de Droit” tuvo lugar los días 8 a 10 de diciembre de 2014 en la Faculté Polydisciplinaire de Tétuán; la moderadora de la Sala 2B, alterando sin explicación alguna el programa previsto, decidió dar la palabra a una intervención en lengua árabe que estaba programada a continuación de la mía, cosa que dicha moderadora sabía muy bien, y que además le fue advertido por algunas personas presentes; en consecuencia decidí no intervenir más en el Coloquio. Con idéntica falta de argumentos, en otra sala se decidió dar preferencia a la lectura de exposiciones en lengua árabe, dejando para el final los anunciados en otras lenguas; po esta razón la Prof. Aurora López tampoco leyó su texto.

2 En M. Alberola 2002, p. 34
\end{abstract}


intelectuales y universitarias como yo, en el sentido de que tienen una idea más igualitaria de los sexos. Ellas representan en realidad los pilares de la familia, alimentan al marido y a los hijos, y son más fuertes que los hombres". Fátima Mernissi ${ }^{3}$

LOS DERECHOS DE LAS MUJERES EN ROMA

Desde el punto de vista de los presupuestos que orientan un coloquio sobre "Gouvernance, citoyenneté \& etat de droit", las mujeres romanas solamente pueden servirnos de referente comparativo, como ejemplo de una sociedad que, por mera razón de su sexo, priva a una parte fundamental de la población de derechos ciudadanos de orden esencial. Pero dado que todavía en nuestros días, en muchos lugares del mundo las mujeres siguen careciendo de plenos derechos, no resultará inútil recordar lo que ocurría en la Roma antigua, aunque sólo sea analizando una institución muy concreta.

Como parece lógico, no voy a entrar en la presentación y discusión de la relegación de las mujeres en Roma si consideramos la falta de derechos que sufren, en grado mayor o menor pero considerable, todo a lo largo de la República y del Imperio. Me voy a limitar a recordar dicha situación por medio de las palabras de tres personas de entonces, dos hombres del s. II a. C., contemporáneos pero de tendencias muy distintas, y una mujer del s. I a. C.

Los dos hombres en cuestión son el cónsul Marco Porcio Catón y el tribuno de la plebe Lucio Valerio; el asunto que los pone en escena es el siguiente: en el año 215 a. C., en pleno fragor de la Guerra Púnica, el tribuno Gayo Opio había propuesto una ley para poner coto al lujo y riquezas de las matronas romanas, según nos cuenta Tito Livio en el precioso comienzo del libro XXXIV de Ab Urbe condita, cuya lectura recomiendo encarecidamente a quienes interese el tema de la situación de las mujeres en Roma y su consideración por parte de los hombres: la Lex Oppia de 215 "establecía que ninguna mujer poseería más de media onza de oro ni llevaría vestimenta de colores variados ni se desplazaría en carruajes tirados por caballos en ciudades o plazas fuertes o a una distancia inferior a una milla salvo con motivo de un acto religioso de carácter público" (Liv. 34, 1). Veinte años después, acabada la guerra, en 195 las mujeres pretenden que la ley sea derogada, y con gran presión por parte de éstas, se entabla un proceso público, en el que Catón, contrario a dicha derogación, pronuncia un tremendo discurso antifemenino, en el que entre otras cosas llega a decir:

\section{Marco Porcio Catón:}

"Si cada uno de nosotros, ciudadanos, hubiese aprendido a mantener sus derechos y su dignidad de marido frente a la propia esposa, tendríamos menos problemas con las mujeres en su conjunto; ahora, nuestra libertad, vencida en casa por la insubordinación de la mujer, es machacada y pisoteada incluso aquí en el foro, y

\footnotetext{
3 F. Mernissi, Marruecos a través de sus mujeres, Madrid, 1990
}

como no fuimos capaces de controlarlas individualmente, nos aterrorizan todas a la vez".

$[\ldots .$.

“Examinad todas las leyes referentes a la mujer con las que vuestros mayores pusieron freno a su incontinencia y la sometieron a su marido; aun constreñidas por todas ellas, a duras penas podéis dominarlas. Qué, si dejáis que desgajen una a una y os arranquen de las manos esas ataduras y se equiparen completamente a sus maridos, ¿creéis que podréis aguantarlas? Desde el momento mismo en que comiencen a ser iguales, serán superiores" (Liv. 34, 2-3)

La derogación de la ley Opia es propuesta por los tribunos de la plebe Marco Fundanio y Lucio Valerio, y Tito Livio nos ofrece el discurso del segundo, verdaderamente sorprendente en labios de un hombre, pues se expresa de forma abierta y que llama la atención a favor de las mujeres, reconociendo al tiempo la inferioridad de derechos que sufren, y sosteniendo que no se las prive de las pocas concesiones que les eran tradicionalmente reconocidas:

Lucio Valerio

"En ellas no pueden recaer ni las magistraturas, ni los sacerdocios, ni los triunfos, $\mathrm{n}$ las condecoraciones, recompensas o despojos de guerra; la elegancia, los adornos, el atavío, éstos son los elementos de distinción de las mujeres; con esto disfrutan y 列 'mundo femenino"' (Liv. 34, 7).

Veamos ahora, aproximadamente un siglo y medio más tarde, la opinión de una matrona romana, Hortensia. La historia de esta mujer, que tuvo la ocasión de ser la primera y única oradora política romana, ha sido estudiada con mucho acierto por Aurora López ${ }^{5}$ a partir sobre todo de tres capítulos de la Historia romana del griego Apiano. Por él sabemos que en el año 42 a. C., encontrándose los triunviros con un déficit público que dificultaba hacer frente a las necesidades de la guerra, promulgaron un duro edicto, en virtud del cual requerían una contribución extraordinaria a las mil cuatrocientas mujeres más ricas de Roma. Ante las severas amenazas que se les

4 Las traducciones de los textos de Tito Livio están tomadas de Historia de Roma desde su fundación. Libros XXXI-XXXV, Traducción y notas de J. A. Villar Vidal, Madrid, 1993.

5 En "Escritoras latinas: las prosistas", en Estudios de filología latina en honor de la profesora Carmen Villanueva Rico, Granada, 1980, pp. 47-69; "La oratoria femenina en Roma a la luz de la actual", en La oratoria en Grecia y Roma: su vigencia en la actualidad, Universidad de verano de Teruel, Teruel, 1989, pp. 97-115; “Hortensia, primera oradora romana”, Florentia Iliberritana 3 (1992) 317-332; No sólo hilaron lana. Escritoras romanas en prosa y en verso, Madrid, Ediciones Clásicas, 1994; De Safo a Alfonsina. Las mujeres en su literatura y en la masculina, Sevilla, ArCiBel Editores, 2008. Cf. también Dorota M. Dutsch, Feminine Discourse in Roman Comedy. On Echoes and Voices, Oxford, Univ. Press, 2008. 
advertían para el posible caso de incumplimiento, intentaron éstas una negociación con los triunviros, valiéndose de las mujeres de sus familias. Al no conseguirlo, enfurecidas se abrieron paso hasta el Foro, llegando a la tribuna de los triunviros, donde Hortensia pronunció un discurso en nombre de todas. Según el resumen de sus palabras que ofrece, en versión griega, Apiano, entre otras cosas decía Hortensia:

“Por qué hemos de pagar tributos nosotras que no tenemos participación en magistraturas, honores, generalatos, ni, en absoluto, en el gobierno de la cosa pública, por las cuales razones os enzarzáis en luchas personales que abocan en calamidades tan grandes? ¿Porque decís que estamos en guerra? ¿Y cuándo no hubo guerras? ¿Cuándo las mujeres han contribuido con tributos? A éstas su propia condición natural las exime de ello en toda la humanidad, y nuestras madres, por encima de su propio ser de mujeres, aportaron su tributo en cierta ocasión y por una sola vez, cuando estabais en peligro de perder todo el imperio e, incluso, la misma ciudad, bajo el acoso cartaginés. Pero entonces realizaron una contribución voluntaria..."

Con toda razón comenta Aurora López que, a pesar de su brevedad, "el resumen de Apiano deja entrever un discurso articulado con gran pericia oratoria, redactado con gran elegancia y precisión de vocabulario, y lleno de ideas interesantes, algunas sorprendentes por su modernidad, hasta tal punto que yo me atrevería a definirlo como uno de los textos fundamentales en defensa de la mujer en el Mundo Antiguo" (López, 2008: 76)

Estas tres opiniones, expresadas por dos hombres y una mujer en los siglos II y I a. C., nos ofrecen una idea cabal de la situación del mujer en Roma, tomando en consideración exclusivamente las pertenecientes a las capas más elevadas de la sociedad. Recordaré, en fin, para perfilar un poco mejor este panorama, el comienzo de una obra muy interesante de Richard A. Bauman, Women and Politics in Ancient Rome:

"A pesar de gozar de una movilidad social considerable bajo la influencia de las ideas etruscas y helenisticas, y gradualmente alcanzando una gran medida de independencia en el derecho privado, las mujeres estuvieron en permanente desventaja en el sector público. Estaban rigurosamente excluidas de la participación oficial en asuntos públicos, como votantes, miembros del senado, detentadoras de magistraturas; la única excepción fueron los sacerdocios, en los que fueros de admitidas cono tiempo inmen tan desfavorable que incluso se dudó si eran ciudadanas romanas" (Bauman, 1994: $1-2)$

Un CARGO RELIGIOSO OCUPADO POR MUJERES: LAS VeSTALES

Absolutamente siempre excluidas de desempeñar los cargos políticos que contemplaba la carrera política o cursus honorum romano desde los tiempos de la
República, fundamentalmente los de aedilis, praetor, quaestor, consul, consularis, censor (cf. Gaudemet, 1967:343-349), y todos los demás, así como excluidas de la consideración de senator o eques, las mujeres tampoco podían ocupar la multiplicidad de altos cargos religiosos que tan grande prestigio y poder real tenían en Roma (Guillén, 1973). Sin que podamos detenernos en el detalle, los poderes religiosos estaban en manos de un número muy importante, bien determinado y bien jerarquizado, de sacerdotes: los pontifices, instituidos por el rey Numa, primero en número de cuatro, después hasta quince, presididos por el pontifex maximus, que tienen en sus manos el nada desdeñable poder de fijar el calendario; el rex sacrorum, heredero de sacrificios antes en manos de los reyes; los flamines; los augures, intérpretes de los signos celestes; los haruspices, adivinos a partir de las vísceras; los fetiales, encargados de intervenir en los tratados o en las declaraciones de guerra (cf. Wissowa, 1912; Bayet, 1969; Guillén, 1973; Montero Herrero, 1990) etc. El poder que todavía en nuestro tiempo tienen los mandatarios religiosos, incluso en sociedades supuestamente democráticas de pleno derecho, y hasta con una Constitución como la española que preconiza el carácter laico del Estado, no hace necesario insistir en el enorme poder político de los sacerdocios en Roma.

Pues bien, es precisamente en el campo de los sacerdocios en el único que, ya desde los tiempos del rey Numa Pompilio (tradicionalmente 715-673), al que se atribuyen grandes reformas culturales y religiosas de antiquísima tradición, encontramos a las mujeres con la posibilidad de ocupar un puesto público de indudable relieve, el colegio de las Vestales.

La información más detallada y preciosa sobre las Vestales, y al mismo tiempo de más agradable lectura, es la que nos ofrece, entre los siglos I y comienzos del II d. C., el filósofo y biógrafo griego Plutarco en su Vida de Numa Pompilio; en él se puede leer lo más interesante sobre estas sacerdotisas de la religión romana:

Por cierto que a Numa atribuyen, igualmente, la consagración de las vírgenes vestales $y$, en general, el culto y veneración relativo al fuego inmortal que atienden éstas, ya sea porque quería encomendar la esencia pura e indestructible del fuego sin contaminación ni mácula, o por asociar lo improductivo y estéril con la virginididad.

[En caso de apagarse el fuego público] dicen que no debe prenderse de otro fuego, sino producirlo de un modo original y nuevo, haciendo arder, a partir del sol, una llama pura y sin mácula. Lo prenden, generalmente, con los espejos ustorios, que se colocan cóncavos desde la parte de lados iguales de un triángulo rectángulo y coinciden en formar un solo centro desde su arco de círculo. Por consiguiente, cuando se encuentran en una posición de cara al sol, de forma que los rayos, reflejándose desde todas partes, convergen y se juntan en el centro, allí fraccionan

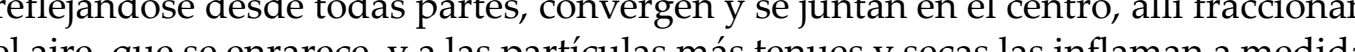
que se ponen delante y, así, el rayo acaba por adquirir cuerpo y centelleo de fuego. 
Según algunos, ninguna otra cosa era custodiada por las vírgenes sagradas aparte de aquel fuego que no se extingue; mas otros aseguran que había ciertas reliquias secretas invisibles para los demás, sobre las que en la Vida de Camilo está escrito todo lo que es lícito inquirir y revelar.

Pues bien, primeramente, dicen que fueron consagradas por Numa Gerania y Verenia, y en segundo lugar, Canuleya y Tarpeya; màs tarde, Servio añadió otras dos a este número, y ya se ha respetado hasta nuestros días tal cifra. Se fijó por el rey, para las vírgenes sagradas, un período de castidad de treinta años, ue celeberar; en la internedian enseñan ellas mismas a otras. Luego, después de ese período, se deja libre a la que lo desee, para casarse y orientarse hacia otra vida diferente, renunciando al ministerio sagrado. Pero dicen que no son muchas las que se acogen a esa dispensa, ni les ruedan bien las cosas a las que se acogen a ella, sino que, sumidas el resto de su vida en el arrepentimiento y la vergüenza, ponen a las otras en tal punto de superstición, que hasta su vejez y muerte viven en la perseverancia y castidad. Las compensó, sin embargo, con importantes honores, entre los que se incluye la facultad de hacer testamento en vida del padre y la gestión de los demás asuntos, pudiendo tramitarlos sin necesidad de representante, como las mujeres de tres hijos. En las salidas se acompañan de lictores. Y si, por azar, se encuentran con un condenado al que llevan a la muerte, no es ajusticiado. Pero debe jurar la virgen que el encuentro ha sido involuntario y fortuito, no intencionado. El que se mete debajo de su litera cuando se las transporta, es reo de muerte.

El castigo que sufren las vírgenes por las demás faltas, son azotes; castigo que El castigo aplica el sumo pontífice a la pecadora, a veces desnuda, con sólo un velo po encima y a oscuras. En cambio, la que mancilla su virginidad es entererrada viva, junto a la puerta que se llama Colina (en la que hay, a la parte interior de la ciudad, una elevación de tierra que se extiende por delante), que significa "montículo" en el idioma de los latinos. Allí se prepara una habitación subterránea de escasas dimensiones, con una bajada desde arriba. Dentro de ella se encuentra una cama vestida, una antorcha ardiendo, y unos pocos alimentos de los que son indispensables para la vida, a saber: pan, agua en un cántaro, leche y aceite; como si tuvieran por sacrílego que muera de hambre una persona consagrada a los más importantes ministerios.

Tras introducir en una litera a la condenada, cubriéndola desde fuera y cerrándola totalmente con correas, de modo que no se pueda oír ninguna voz, la transportan a través de la plaza. Todos se apartan en silencio y la acompañan calladamente, llenos de impresionante tristeza. No existe otro espectáculo más sobrecogedor, $n$ la ciudad vive ningún día más triste que aquél. Cuando llega la litera hasta el lugar, los asistentes desatan las correas y el sacerdote oficiante, después de hacer ciertas inefables imprecaciones, la coloca sobre una escalera que conduce hacia la morada de abajo. Entonces, se retira el junto con los demás sacerdotes. $Y$, una vez que aquélla ha descendido, se destruye la escalera y se cubre la habitación echándose por encima abundante tierra, hasta que queda el lugar a ras con el resto del montículo. Así son castigadas las que pierden la sagrada virginidad.

Se cuenta que también levantó Numa en círculo el templo de Vesta, como recinto para el fuergo que no se extingue, imitando no la forma de la tierra, como que es Vesta, sino la de todo el Universo, en cuyo centro creen los pitagóricos que se asienta el fuego, y lo llaman "Hestia" y "unidad". La tierra, según ellos, que no está inmóvil ni en el centro de la rotación cósmica, sino que gira en círculo alrededor del fuego, no es una de las partes más valiosas ni primeras de Universo

[...] (Plut., Numa 9-11)

Este curioso sacerdocio femenino, no el único que existe en Roma, pero si el más importante y de mayor vigencia a lo largo de todos los tiempos de la Urbe (cf. Rose 1926 \& 1928; Giannelli, 1933; Worsfold, 1934; Guillén, 1973: 39-52; Martínez López, 1988 Cantarella, 1991: 136-140; Wildfang, 2006), tuvo una importancia indudable, semejante a la de los más notables sacerdocios masculinos. Aulo Gelio dedica el capítulo I 12 de sus Noches Áticas a aspectos que atañen a las vestales, como los referentes a su edad de elección, requisitos de sus familias de procedencia, modo de selección, etc. hace referencia a una ley Papia, que no conocemos en realidad, la cual regulaba la elección de cada vestal entre un número de hasta veinte niñas, de edad entre los seis y los diez años, que debían carecer de defectos físicos, amén de pertenecer a familias que cumplieran con ciertos requisitos. Son todos detalles de sobra conocidos, sobre los que existe una amplia literatura. En todo caso, merece la pena subrayar el hecho de que, entregando una parte fundamental de sus vidas al culto público de la diosa Vesta y bajo rigurosa imposición de mantener su virginidad durante todo ese tiempo, las vestales son gratificadas con una serie de derechos y reconocimientos de los que carecen las romanas, incluso las de condición libre, como únicas mujeres sui iuris, esto es, libres de la patria potestad y con especiales atribuciones de índole jurídica, como la capacidad de hacer testamento sin intervención de un tutor.

El profundo respeto con que se las rodea en Roma queda de manifiesto en el texto de Plutarco que hemos recordado, y en otros muchos autores de diversas épocas (cf. Guillén, 1973: 39-52). Poseen, pues, un respeto y veneración, que vemos reflejados por ejemplo en la manera de relatar Tito Livio su creación por el rey Numa, a continuación de los tres flamines principales, los de Júpiter, Marte y Quirino: “Nombró las Vestales, un sacerdocio oriundo de Alba y relacionado con la familia del fundador; para que atendieran permanentemente a su ministerio en el templo les fijo una dote a cargo del

6 La traducción del texto de Plutarco está tomada de Vidas paralelas I Teseo - Rómulo Licurgo Numa, Introducción general, traducción y notas por A. Pérez Jiménez, Madrid, Gredos, 1985. 
Estado; con la virginidad y otras ceremonias las hizo venerables y sagradas" (Liv. 1 $20)^{7}$.

De modo semejante, en fin, cuando Cicerón en su De legibus se proponía codificar una legislación adecuada para Roma, trataba con ese mismo respeto y veneración que antes decíamos a las vestales: "El haber varios sacerdotes para todos los dioses y otros especiales para cada uno facilita el dictamen sobre el rito justo, y los cultos que hay que celebrar. Y ya que Vesta ha tomado el significado de "hogar de la ciudad" [...] cuiden de su culto seis vírgenes, a fin de que se vigile mejor la custodia del fuego y entiendan las mujeres cómo la naturaleza femenina se compadece con la absoluta pureza" (De leg. 2,29$)^{8}$.

Sin embargo, y a modo de conclusión, una reflexión pausada sobre la razón de ser de este importante sacerdocio femenino, en una sociedad de principios profundamente patriarcales, que si bien tuvo que ir pactando a lo largo de su prolongado desarrollo histórico la concesión de diversos derechos a las mujeres de las clases superiores, pero nunca plenos derechos políticos, no viene a ser más que la excepción que confirma la regla concerniente a la exclusión de las mujeres romanas del disfrute de los derechos fundamentales legalmente reconocidos a los ciudadanos. Esto se demuestra con la terrible dureza con la que fueron siempre castigadas las vestales cuando faltaban a su obligación de permanecer vírgenes: como ya hemos visto en Plutarco, se las sepultaba vivas, con un rito de crueldad sin límites. La historia de Roma recordaba los nombres de algunas vestales, no muchas en número, pero sí a lo largo de todo su desarrollo, sepultadas vivas, de acuerdo con la norma establecida, por haber perdido su virginidad (cf. Guillén, 1973: 39-52; Cantarella, 1991: 136-137). De este modo, su incumplimiento del deber públicamente impuesto, que las hacía extraordinaria y aparentemente superiores al resto de las mujeres, quedaba sujeto a un castigo ejemplar, que ha estudiado Eva Cantarella de manera muy acertada, en su libro I supplizi capitali in Grecia e a Roma, como "paradigma del castigo de las mujeres comunes" ${ }^{9}$

\section{REFERENCIAS BIBLIOGRÁficAs}

Bauman, R. A. , Women and Politics in Ancient Rome, London, Routledge, 1994.

7 Traducción tomada de Tito Livio, Historia de Roma desde la fundación de la ciudad (Ab Vrbe condita). Libros I-II, Texto revisado, trad., intr. y notas por A. Fontán, Madrid, C. S. I. C., 1987.

8 Traducción tomada de Cicerón, Las leyes, Trad., intr. y notas por Á. d'Ors, Madrid, Instituto de Estudios Políticos, 1970.

9 Cantarella, 1991: 137: “Ma, al di là della cronaca, quello che qui interessa è l'analogia tra la morte delle Vestali e quella delle mogli degli inflessibili cittadini romani, o quantomeno di quelli che decidevano di essere inflessibili. E non solo la morte delle loro mogli: anche quelle delle loro figlie e delle loro sorelle. A Roma infatti, cosí como in Grecia, una donna non commentteva reato solo se veniva meno alla fede coniugale, ma più in generale, independentemente dal fatto che fosse sposata ogni qualvolta intratteneva un rapporto sessuale al di fuori del matrimonio".
Bayet, J., Histoire politique et psychologique de la religion romaine, Paris, Payot, 1969.

Beard, M., "The Sexual Status of Vestal Virgins", JRS 70 (1980) 12-27.

Cantarella, E., I supplizi capitali in Grecia e a Roma. Origini e funzioni della pena di morte nell'antichità classica, Milano, Rizzoli, 1991

Cicerón, Las leyes, Trad., intr. y notas por Á. d’Ors, Madrid, Instituto de Estudios Políticos, 1970.

Dutsch, D. M., Feminine Discourse in Roman Comedy. On Echoes and Voices, Oxford, Univ. Press, 2008

Gaudemet, J., Institutions de l'Antiquité, Paris, Sirey, 1967.

Giannelli, G., Il sacerdozio delle Vestali romane, Firenze, Galletti e Cocci, 1913.

Guillén, J., “Los sacerdotes romanos”, Helmantica 24 (1973) 5-76.

-, "Las Vestales", en Vrbs Roma. Vida y costumbres de los rtomanos. III Religión y ejército Salamanca, Ediciones Sígueme, 1985, pp. 316-325.

Guizzi, F., Aspetti giuridici del sacerdozio romano. Il sacerdoizio di Vesta, Napoli, E. Jovene, 1968.

López, "Escritoras latinas: las prosistas", en Estudios de filología latina en honor de la profesora Carmen Villanueva Rico, Granada, Universidad, 1980, pp. 47-69.

-, "La oratoria femenina en Roma a la luz de la actual", en La oratoria en Grecia y Roma: su vigencia en la actualidad, Universidad de verano de Teruel, Teruel, 1989, pp. 97-115.

_, "Hortensia, primera oradora romana", Florentia Iliberritana 3 (1992) 317-332.

-, No sólo hilaron lana. Escritoras romanas en prosa y en verso, Madrid, Ediciones Clásicas, 1994.

-, De Safo a Alfonsina. Las mujeres en su literatura y en la masculina, Sevilla, ArCiBel Editores, 2008

Martínez López, C., "Virginidad-Fecundidad: en torno al suplicio de las Vestales”, SHHA 6 (1988) 137-144

Montero Herrero, S., La religión romana antigua, Madrid, Akal, 1990.

Plutarco, Vidas paralelas I Teseo - Rómulo Licurgo - Numa, Introducción general, traducción y notas por A. Pérez Jiménez, Madrid, Gredos, 1985.

Rose, H. J. , “De Virginibus Vestalibus”, Mnemosyne n. s. 54 (1926) 440-448; 56 (1978) 79-80.

Tito Livio, Historia de Roma desde la fundación de la ciudad (Ab Vrbe condita). Libros I-II, Texto revisado, trad., intr. y notas por A. Fontán, Madrid, C. S. I. C., 1987.

-, Historia de Roma desde su fundación. Libros XXXI-XXXV, Traducción y notas de J. A. Villar Vidal, Madrid, 1993.

Wildfang, R. L. , Rome's Vestal Virgins. A Study of Rome's Vestal priestesses in the late Republic and early Empire, Abingdon, Routledge, 2006

Wissowa, G., Religion und Kultus der Römer, München, C. H. Beck, 1912 
Worsfold, T. C., The History of the Vestal Virgins of Rome, Whitefish, Kessinger Publishing, 1997. 